\section{Survival in COPD}

\section{S163 THE 'OBESITY PARADOX' IN CHRONIC OBSTRUCTIVE PULMONARY DISEASE}

doi:10.1136/thx.2010.150953.14

${ }^{1} \mathrm{P} F$ Collins, ${ }^{1} \mathrm{R} J$ Stratton, ${ }^{2} \mathrm{R}$ Kurukulaaratchy, ${ }^{1} \mathrm{M}$ Elia. ${ }^{1}$ Institute of Human Nutrition, School of Medicine, University of Southampton, Southampton, England, UK; ${ }^{2}$ Respiratory Medicine, Southampton University Hospital NHS Trust, Southampton, England, Uk

Poor nutritional status in chronic obstructive pulmonary disease (COPD) is associated with increased mortality independently of disease-severity (Collins et al). ${ }^{1}$ Epidemiological studies have suggested a protective role of obesity against mortality in COPD (Vestbo et al) $)^{2}$ which is contrary to data from the general population where obesity is associated with decreased life expectancy. This relationship has been referred to as the 'obesity paradox' and has been demonstrated in a number of chronic wasting conditions (Kalantar-Zadeh et al). ${ }^{3}$ This study investigated the existence of the obesity paradox in outpatients with COPD by examining the effect of body mass index (BMI) on 1-year healthcare use and clinical outcome in terms of hospital admission rates, length of hospital stay, outpatient appointments and mortality. BMI was assessed in 424 outpatients with COPD, with measurements performed by specialist respiratory nurses during outpatient clinics. 1-year healthcare use was retrospectively collected from the date of BMI measurement. Abstract S163 Table 1 Patients classified as overweight $\left(25.0-29.9 \mathrm{~kg} / \mathrm{m}^{2}\right)$ or obese $\left(>30 \mathrm{~kg} / \mathrm{m}^{2}\right)$ experienced significantly fewer emergency hospital admissions, as well as a reduced length of hospital stay, in comparison to normal weight $\left(20.0-24.9 \mathrm{~kg} / \mathrm{m}^{2}\right)$ or underweight $\left(<20 \mathrm{~kg} / \mathrm{m}^{2}\right)$ outpatients. There was a significant negative trend between BMI classification and mortality. This study supports the existence of the 'obesity paradox' in COPD, not only in relation to reduced 1 year mortality rates but also in terms of reduced emergency hospital admissions and reduced length of hospital stay.

\section{Abstract S163 Table 1}

\begin{tabular}{llllll}
\hline BMI category $\left(\mathrm{kg} / \mathrm{m}^{2}\right)$ & $<20$ & $20-24.9$ & $25-29.9$ & $>30$ \\
& $(\mathrm{n}=67)$ & $(\mathrm{n}=144)$ & $(\mathrm{n}=120)$ & $(\mathrm{n}=93)$ & $\mathrm{p}$ \\
No. EM admissions per patient & $1.5(3.7)$ & $1.2(1.7)$ & $0.74(1.4)$ & $0.71(1.1)$ & $0.011^{*}$ \\
EM LOS (days per patient) & $6.5(12.8)$ & $9.6(19.3)$ & $5.3(17.3)$ & $3.6(9.0)$ & $0.034^{*}$ \\
No. ELEC admissions per patient & $0.33(0.75)$ & $0.22(0.71)$ & $0.20(0.67)$ & $0.39(0.90)$ & $0.216^{*}$ \\
ELEC LOS (days per patient) & $1.94(7.9)$ & $0.59(2.6)$ & $0.48(3.2)$ & $2.1(13.0)$ & $0.240^{*}$ \\
OPA per patient & $3.4(2.5)$ & $4.1(3.4)$ & $3.4(2.6)$ & $3.5(2.6)$ & $0.163^{*}$ \\
1-year mortality (\%) & 21 & 15 & 5 & 4 & $<0.001 \dagger$ \\
\hline
\end{tabular}

Values are mean $\pm S D$

${ }^{*}$ ANOVA.

$\dagger X^{2}$ p-trent.

No, number; EM, emergency; ELEC, elective; LOs, length of stay; OPA, outpatient appointments.

Funding Funded by an unrestricted educational grant from Nutricia.

\section{REFERENCES}

1. Collins PF, et al. Clinical Nutrition, abstract 2010. In Press.

2. Vestbo J, et al. Am J Respir Crit Care Med 2006;173:79-83.

3. Kalantar-Zadeh K, et al. Curr Opin Clin Nutr Metab Care 2007;10:433-42.

\section{S164 \\ DIMINISHED LEFT VENTRICULAR END-DIASTOLIC DIMENSIONS PREDICT AN AMPLIFIED RISK OF DEATH IN CHRONIC OBSTRUCTIVE PULMONARY DISEASE}

doi:10.1136/thx.2010.150953.15

M Mendonca, J Brown, M Rashid, H Z Ling, S Kang, A Cheng, E Boston-griffiths, M Okorie, M Thomas, S Woldman, H Booth, Do okonko. University College London Hospital, London, UK

Background Left ventricular (LV) dimensions are markedly attenuated in chronic obstructive pulmonary disease (COPD) possibly due

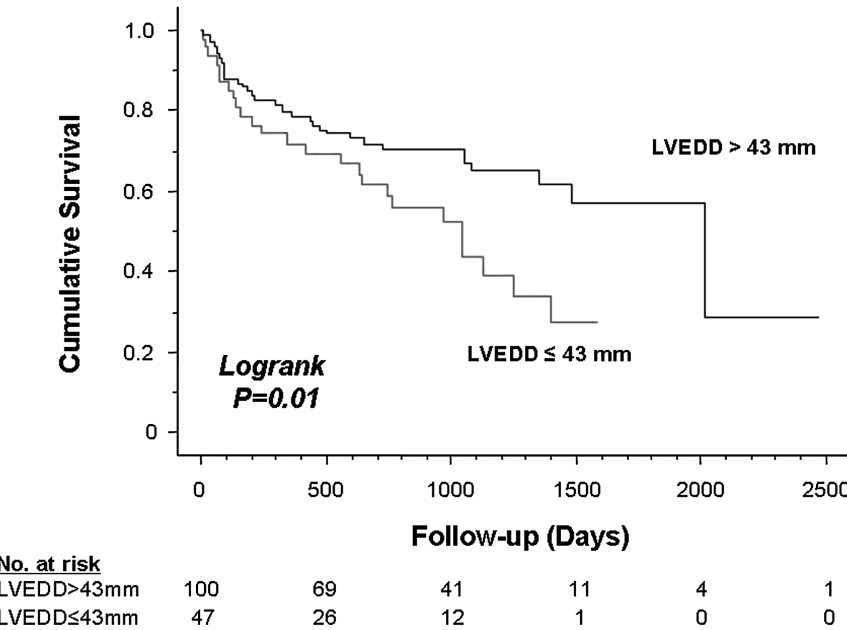

Abstract S164 Figure 1

to impairments in LV filling that result from increased pulmonary vascular resistance, ventricular interdependence, diastolic dysfunction or incessant tachycardia. Whether reductions in LV size carry adverse prognostic implications in this cohort is unclear.

Methods We analysed the relation between echocardiographic indices and mortality in $147 \mathrm{COPD}$ patients (mean [ $\pm \mathrm{SD}$ ] age $76 \pm 10$ years, forced expiratory volume in $1 \mathrm{~s}$ [FEV1] $0.85 \pm 0.341$, forced vital capacity [FVC] $1.44 \pm 0.601$, FEV1/FVC 0.62 \pm 0.16 , LV ejection fraction [LVEF] $56 \pm 12 \%$ ) with homogenous right ventricular $(42 \pm 14 \mathrm{~mm} \mathrm{Hg})$ and pulmonary arterial systolic $(45 \pm 17 \mathrm{~mm}$ $\mathrm{Hg})$ pressures.

Results Decreased LV end-diastolic (LVEDD $\leq 37 \mathrm{~mm}$ ) and endsystolic (LVESD $\leq 25 \mathrm{~mm}$ ) diameters, ejection fraction $(<45 \%)$, and diastolic function (E/A ratio $<1$ or $>2$ ) were evident in $10 \%, 14 \%$, $18 \%$ and $71 \%$ of patients, respectively. Lower LVEDDs correlated significantly to lower LVESDs $(r=0.83)$, higher LVEFs $(r=-0.54)$, lower FEV1s $(r=0.29)$, and lower FVCs $(r=0.20)$ but not to age, right ventricular systolic pressures or pulmonary arterial pressures. Over a mean follow-up of $26 \pm 18$ months, 60 (41\%) patients died. Only a lower LVEDD predicted increased mortality $\left(c^{2} 4.4, p=0.03\right)$ with each $1 \mathrm{~mm}$ decrement in LVEDD conferring a $3 \%$ escalated risk of death. An LVEDD $\leq 43 \mathrm{~mm}$ optimally predicted mortality and was associated with an $89 \%$ reduction in survival compared to an LVEDD $>43 \mathrm{~mm}$ (Abstract S164 Figure 1). No variable affected the prognostic impact of LVEDDs in adjusted analyses.

Conclusions Attenuations in left ventricular end-diastolic diameter forecast an enhanced risk of death in patients with COPD, irrespective of lung function and pulmonary arterial pressures. Improving LV filing and dimensions in this cohort may augment survival.

\section{S165 DEPRIVATION IS AN INDEPENDENT PREDICTOR OF 1-YEAR MORTALITY IN OUTPATIENTS WITH CHRONIC OBSTRUCTIVE PULMONARY DISEASE}

doi:10.1136/thx.2010.150953.16

${ }^{1} \mathrm{P} F$ Collins, ${ }^{1} \mathrm{R}$ J Stratton, ${ }^{2} \mathrm{R}$ Kurukulaaratchy, ${ }^{1} \mathrm{M}$ Elia. ${ }^{1}$ Institute of Human Nutrition, School of Medicine, University of Southampton, Southampton, England, UK; ${ }^{2}$ Respiratory Medicine, Southampton University Hospital NHS Trust, Southampton, England, UK

Deprivation is linked to increased incidence in a number of chronic diseases but its relationship to chronic obstructive pulmonary disease (COPD) is uncertain despite suggestions that the socioeconomic gradient seen in COPD is as great, if not greater, than any 